\title{
Prevalence and predictors of cigarette smoking among Greek urban adolescents: A cross-sectional study
}

\author{
Athonasia Liozidoul, ${ }^{1,2}$ Niki Dimou ${ }^{3}$, Areti Lioupa ${ }^{4}$, Panagiotis Behrakis ${ }^{1,5}$
}

\begin{abstract}
INTRODUCTION Studies on smoking prevalence of Greek adolescents are sparse and ambiguous. We aimed to investigate prevalence and predictors of cigarette smoking among Greek adolescents.

METHODS We conducted a cross-sectional study of 1.802 randomly selected students in the cities of Athens and Thessaloniki in Greece in 2013-2014. Multistage sampling with quotas was used with regard to the geographical distribution of the target population gender and grade. Data were collected by a self-completed questionnaire. Multiple logistic regression analysis was applied to evaluate the association between selected variables and the likelihood of being a current smoker.

RESULTS Cigarette smoking was reported by 18.2\% (95\% CI=16.4 - 20.0); 8.1\% (95\% CI=6.2 - 10.0) of Gymnasium and 26.1\% (95\% CI=23.4 - 28.8) of Lyceum students reported being smokers. An estimated 38.0\% (95\% CI=35.8 - 40.2) had ever tried cigarette, 27.1\% (95\% CI=25.1 - 29.2) hookah and $17.7 \%(95 \% \mathrm{CI}=15.9$ - 19.5) an electronic cigarette. Older age (OR=11.59; 95\% CI [6.25, 21.50], parental tobacco use $(\mathrm{OR}=1.71 ; 95 \%$ CI $[1.19,2.46])$, sibling tobacco use (OR=2.07; 95\% CI [1.43, $2.99]$, teachers' tobacco use $(\mathrm{OR}=1.97 ; 95 \% \mathrm{CI}[1.23,3.17])$, exposure to smoking through the media $(\mathrm{OR}=1.48$; 95\% CI[1.03,2.14] and tobacco promotion activities (OR=3.73;95\% CI[2.88,4.83] were associated with current smoking.

concLusions Greek adolescents report lower smoking rates than previously reported, yet it is a population experimenting with tobacco products. Electronic cigarette emerged as the third most likely product of experimentation. The social origin of smoking behavior is confirmed, as well as the imperative need to encourage tobacco-free school policies and bans on tobacco advertising, promotion and sponsorship.
\end{abstract}

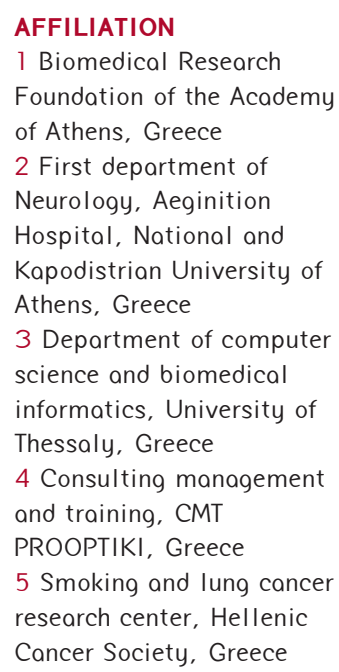

AFFILIATION

1 Biomedical Research

Foundation of the Academy of Athens, Greece

2 First department of Neurology, Aeginition Hospital, National and Kapodistrian University of Athens, Greece

3 Department of computer science and biomedical informatics, University of Thessaly, Greece

4 Consulting management and training, CMT PROOPTIKI, Greece 5 Smoking and lung cancer research center, Hellenic Concer Society, Greece

\section{CORRESPONDENCE TO}

Liozidou A. Biomedical Research Foundation of the Academy of Athens (BRFAA), 4 Soranou Ephessiou st. 115 27. Athens, Greece, athanasialiozidou@gmail. com

KEY WORDS adolescence, cigarette smoking, prevalence, Greece, e-cigarettes

\section{INTRODUCTION}

Tobacco use is a leading preventable risk factor for many chronic diseases with adolescence noted as the most crucial period of experimentation with tobacco products ${ }^{1}$. Given that half of smokers will die prematurely from a tobacco related disease $^{2}$, it is alarming that prevalence of tobacco use during adolescence in the European region is among the highest in the world ${ }^{3}$.

Studies evaluating smoking prevalence among Greek teenagers are sparse and ambiguous. For instance, while a previous study from Arvanitidou et al. ${ }^{4}$ gave a smoking rate of $34.3 \%$ for male urban adolescents and a smoking rate of $40.9 \%$ for female urban adolescents aged 12-18 years old, a concurrent study by Giannakopoulos et al. ${ }^{5}$ reported a smoking rate of $9.1 \%$ for Greek urban adolescents aged 1217 years old in 2009. According to the Global Youth Tobacco Survey, an internationally applied protocol for the monitoring of smoking prevalence among 13-15 year olds, a minor downward trend is observed for Greek adolescents (10.4\% to $10.1 \%$ from 2005 to 2013 ) but an ascending trend among female adolescent smokers has been noted (from 9.0\% in 2005 to $9.9 \%$ in 2013), trends which have also been depicted in other European countries as well ${ }^{6-7}$. A large number of intrapersonal, social and cultural factors have been associated with tobacco use and cigarette smoking in adolescence ${ }^{1}$. Although some of them have been identified within the Greek environment, the relationship between tobacco use and adolescence has been insufficiently investigated in Greece. The few data collected have highlighted the role of male gender, parental smoking status, pocket money ${ }^{8}$, friends and sibling smoking status ${ }^{9}$ and the existence of emotional and behavioral problems ${ }^{5}$ as predictors of cigarette smoking. On the contrary, the effect of tobacco industry influences as well as knowledge of adolescents with regards to the health hazards 
of smoking lack a thorough investigation. In Greece, a smoking ban covers all schools, all indoor public places (restaurants, night clubs, bars, etc.), all private or public sector working places and all means of public transport $\mathrm{t}^{10}$. Yet, clean indoor air policies are poorly enforced. In practice, the restriction of smoking in Greek schools vary significantly, from schools with no enforcement at all, to schools where smoking is either prohibited at all places or at all places except for the staff room or at all places except for specific spaces for the smokers within the school unit (smoking rooms) -despite the existence of a comprehensive ban. All of the above make Greece an ideal country model to investigate if and how adolescent smoking may be associated with exposure to teachers' smoking.

In light of the above, we sought a dual objective; to investigate the prevalence of current cigarette smoking for adolescents aged 12-18 years old of the two major cities of Greece, Athens and Thessaloniki, and to explore the predictors of current cigarette smoking for the same population.

\section{METHODS}

\section{Study Design and Sampling Procedure}

Our survey was administered to a representative sample of secondary education students in the two biggest cities of Greece (i.e. Athens and Thessaloniki). Secondary education in Greece is comprised of two levels, with three grades each: gymnasium (12 to 15 year olds) and lyceum (approximate age of 16 to 18 year olds). Schooling through gymnasium is compulsory, after which students can either attend a general lyceum or vocational training. Our methodology was based on a two stage stratified clustered design with schools as the primary sampling units and classes as the secondary units. A listing of all public and private secondary education schools by grade in Athens and Thessaloniki for the 20132014 school years was used as the sampling frame. Schools of special education, as well as music and vocational schools were excluded as their students are quite heterogeneous (for instance students older than 18 years) which could result in biased overall estimates.

The sample design featured three levels of stratification: city, regional directorate of secondary education and grade. Within each stratum, for each grade (grade 1-3 for gymnasium or lyceum), schools were selected with probability proportional to their size, with the selection done independently for each grade so that some schools may have provided classes at more than one grade. The selection of the secondary sampling units (classes) was conducted by field staff that randomly selected one class in the desired grade. All students attending school the day the survey was administered were eligible to participate. Student participation was voluntary and anonymous and they provided their verbal assent. Prior students' acceptance parents and guardians were fully informed about the objectives and methods of the study and signed a consent form. The Greek Ministry of Education through the Institute of Education Policy provided support and approved the particular study (protocol approval No. 63377/G2/24-04-2014).

\section{Procedures}

A self-reported questionnaire was developed for the study. The questionnaire retrieved information regarding gender, age, current smoking status, experimentation with other tobacco products, parental, siblings, friends and teachers smoking, awareness of the health consequences of smoking, exposure to smoking through the entertainment media (cinema, television, music industry) and exposure to tobacco industry promotion activities.

A total of 1.802 students enrolled in the study of which 992 were female (55.0\%). All students of a selected class returned a completed self-administered questionnaire. No questionnaire was excluded due to incompleteness or incorrect responses. Of the respondents, 794 participants were gymnasium students and 1008 participants were lyceum students.

\section{Measures and Definitions}

The individuals who responded that they had smoked at least one cigarette during the past 30 days were classified as current cigarette smokers; a widely used definition for current smoking ${ }^{11-13}$. Exposure to smoking through entertainment media was measured retrospectively during the last 30 days and was defined by means of a cinema movie, television series and/or a music clip ${ }^{14}$. We used a methodology that has been previously described ${ }^{15}$ to measure the exposure to promotion activities of the tobacco industry: "Have you ever been approached by individuals working on promotion companies to present you a particular brand of cigarettes or to offer you free products that advertise a brand of cigarettes (e.g. hats, lighters, pens, t-shirts)?".

\section{Statistical Analysis}

Frequencies and relative frequencies were calculated for all the questions. Pearson's $\mathrm{x} 2$ test was used to evaluate the potential association of current smoking status with grade and gender. Multiple logistic regression analysis was applied to evaluate the association between social influences, awareness of health hazards, exposure to smoking through entertainment media, exposure to promotion activities of the tobacco industry and the likelihood of being a current smoker. The analysis 
Table 1. Current cigarette smoking and experimentation with other tobacco products among urban adolescents, Greece 2014.

\begin{tabular}{|c|c|c|c|c|c|c|}
\hline & $\begin{array}{l}\text { Evertried a } \\
\text { cigarette }(95 \% \text { CI })\end{array}$ & $\begin{array}{l}\text { Current cigaretle use } \\
(95 \% \mathrm{CI})\end{array}$ & $\begin{array}{l}\text { Ever Iried a hookah } \\
(95 \% \text { CI })\end{array}$ & $\begin{array}{l}\text { Ever Tried an } \\
\text { e cigaretle } \\
(95 \% \text { CI })\end{array}$ & $\begin{array}{l}\text { Ever tried a } \\
\text { cigar }(95 \% \text { CI })\end{array}$ & $\begin{array}{l}\text { Ever tried a } \\
\text { pipe }(95 \% \text { CI })\end{array}$ \\
\hline \multicolumn{7}{|c|}{ Gymnasium } \\
\hline lst & $\begin{array}{l}10.6 \% \\
(6.9-14.3)\end{array}$ & $\begin{array}{l}4.6 \% \\
(2.1-7.1)\end{array}$ & $\begin{array}{l}5.3 \% \\
(2.6-8.0)\end{array}$ & $\begin{array}{l}4.9 \% \\
(2.3-7.5)\end{array}$ & $\begin{array}{l}2.3 \% \\
(0.5-4.1)\end{array}$ & $1.5 \%(0.0-3.0)$ \\
\hline $2 n d$ & $\begin{array}{l}22.4 \% \\
(17.5-27.4)\end{array}$ & $\begin{array}{l}9.6 \% \\
(6.1-13.1)\end{array}$ & $\begin{array}{l}12.1 \% \\
(8.2-16.0)\end{array}$ & $\begin{array}{l}6.3 \% \\
(3.4-9.2)\end{array}$ & $\begin{array}{l}2.6 \% \\
(0.7-4.5)\end{array}$ & $\begin{array}{l}1.5 \% \\
(0.1-2.9)\end{array}$ \\
\hline $3 r d$ & $\begin{array}{l}28.2 \% \\
(22.7-33.7)\end{array}$ & $\begin{array}{l}10.0 \% \\
(6.4-13.7)\end{array}$ & $\begin{array}{l}25.9 \% \\
(20.6-31.2)\end{array}$ & $\begin{array}{l}17.4 \% \\
(12.8-22.0)\end{array}$ & $\begin{array}{l}4.2 \% \\
(1.8-6.6)\end{array}$ & $\begin{array}{l}0.8 \% \\
(0.0-1.9)\end{array}$ \\
\hline \multicolumn{7}{|c|}{ Lyceum } \\
\hline lst & $\begin{array}{l}39.7 \% \\
(34.4-45.0)\end{array}$ & $\begin{array}{l}18.5 \% \\
(14.3-22.7)\end{array}$ & $\begin{array}{l}30.3 \% \\
(25.3-35.3)\end{array}$ & $\begin{array}{l}21.2 \% \\
(16.8-25.6)\end{array}$ & $\begin{array}{l}15.8 \% \\
(11.9-19.7)\end{array}$ & $\begin{array}{l}3.9 \% \\
(1.8-6.0)\end{array}$ \\
\hline $2 n d$ & $\begin{array}{l}48.9 \% \\
(43.4-54.4)\end{array}$ & $\begin{array}{l}23.3 \% \\
(18.6-28.0)\end{array}$ & $\begin{array}{l}33.2 \% \\
(28.0-38.4)\end{array}$ & $\begin{array}{l}22.4 \% \\
(17.8-27.0)\end{array}$ & $\begin{array}{l}15.0 \% \\
(11.0-19.0)\end{array}$ & $\begin{array}{l}4.2 \% \\
(2.0-6.4)\end{array}$ \\
\hline $3 r d$ & $\begin{array}{l}65.2 \% \\
(60.3-70.1)\end{array}$ & $\begin{array}{l}35.3 \% \\
(30.4-40.2)\end{array}$ & $\begin{array}{l}46.6 \% \\
(41.5-51.7)\end{array}$ & $\begin{array}{l}28.2 \% \\
(23.6-32.8)\end{array}$ & $\begin{array}{l}26.0 \% \\
(21.5-30.5)\end{array}$ & $\begin{array}{l}6.6 \% \\
(4.1-9.2)\end{array}$ \\
\hline Total & $\begin{array}{l}38.0 \% \\
(35.8-40.2)\end{array}$ & $\begin{array}{l}18.2 \% \\
(16.4-20.0)\end{array}$ & $\begin{array}{l}27.1 \% \\
(25.1-29.2)\end{array}$ & $\begin{array}{l}17.7 \% \\
(15.9-19.5)\end{array}$ & $\begin{array}{l}12.1 \% \\
(10.6-13.6)\end{array}$ & $\begin{array}{l}3.3 \% \\
(2.5-4.1)\end{array}$ \\
\hline
\end{tabular}

accounted for the potential effect of gender and grade. In all analyses statistically significant results were declared as those with a P-value $<0.05$. For all analyses, the statistical package Stata 10 (Stata Corporation, College Station, Texas, USA) was used.

\section{RESULTS}

\section{Prevalence of current cigarette smoking}

Current cigarette smoking was reported by $18.2 \%$ (95\% $\mathrm{CI}=16.4-20.0)$ of secondary education students. Of those students reporting current cigarette smoking 20.1\% (95\% CI $=17.3 \%$ to $22.9 \%$ ) were males and $16.5 \%$ (95\% CI $=14.2$ - 18.8) were females. The lowest rate of current cigarette smoking was reported by the students attending the 1st grade of gymnasium $(4.6 \%, 95 \% \mathrm{CI}=2.1-7.1)$ while the highest rate was reported by the students attending the 3rd grade of lyceum $(35.3 \%, 95 \% \mathrm{CI}=30.4 \%-40.2)$. A variation on smoking prevalence between the two cities was observed, with Athens presenting higher percentages of current smoking status $(20.3 \%, 95 \% \mathrm{CI}=18.0$ - 22.6) vs. Thessaloniki (14.4\%, 95\% CI=11.7 - 17.1).

\section{Experimentation with other tobacco products}

With regards to experimentation with tobacco products, $38.0 \%$ (95\% CI $=35.8$ - 40.2) had ever tried a cigarette, $27.1 \%$ (95\% $\mathrm{CI}=25.1-29.2)$ had ever tried hookah, $17.7 \%$ (95\% CI=15.9 - 19.5) had ever tried an electronic cigarette, $12.1 \%$ (95\%
Table 2. Unadjusted logistic regression model assessing the association of gender and grade with smoking status ofGreek adolescents.

\begin{tabular}{|c|c|c|c|}
\hline Dependent I ariables & $\begin{array}{l}\text { Odds } \\
\text { Ratio }\end{array}$ & $95 \%$ C.I. & p-value \\
\hline \multicolumn{4}{|c|}{ Current Cigarette Smokers (a) } \\
\hline Boy & 1 & & \\
\hline Girl & 0.777 & $(0.611-0.988)$ & 0.039 \\
\hline \multicolumn{4}{|c|}{ Current Cigarette Smokers (a) } \\
\hline 1st Grade Gymnasium* & 1 & & \\
\hline 2nd Grade Gymnasium & 2.193 & $(1.082-4.444)$ & 0.029 \\
\hline 3rd Grade Gymnasium & 2.398 & $(1.182-4.864)$ & 0.015 \\
\hline 1st Grade Lyceum & 4.758 & $(2.503-9.048)$ & $<0.001$ \\
\hline 2nd Grade Lyceum & 6.418 & $(3.398-12.123)$ & $<0.001$ \\
\hline 3rd Grade Lyceum & 11.588 & $(6.246-21.498)$ & $<0.001$ \\
\hline
\end{tabular}

(a) Individuals who responded that they had smoked at least one cigarette during the past 30 days.

$\mathrm{CI}=10.6$ - 13.6) had ever tried a cigar and 3.3\% (95\% CI=2.5 - 4.1) had ever tried a pipe (Table 1). Notably, an estimated $8.5 \%(95 \%$ CI $=6.6-10.4)$ had experimented only with electronic cigarette.

\section{Predictors of current cigarettesmoking}

As shown in Table 2, females had a lower risk of being current smokers $(\mathrm{OR}=0.78$; CI $[0.61,0.99])$ as compared to males, while age emerged as a very strong predictor of current 
Research Article

Table 3. Adjusted logistic regression model assessing the impact of the social environment as well as the impact of the awareness of health hazards of smoking on current smoking statusl of Greek urban adolescents

Independent Variables Odds
Ratio

Model 1: The impact of the social environment

\section{Gender}

Male

Female

1

1st Grade Gymnasium

\section{2nd Grade Gymnasium}

3rd Grade Gymnasium

0.606

0.432

0.849

Grade

1st Grade Lyceum

0.816

$0.319 \quad 2.084$

0.671

1.128

$0.449 \quad 2.838$

0.797

1.413

$0.616 \quad 3.242$

0.415

2nd Grade Lyceum

3rd Grade Lyceum

No

One parent

1.692

0.743

2.404

1.076

3.853

0.210

Parental Smoking

1

$1.713 \quad 1.191$

Siblings' Smoking

No 1

Yes

1

$\begin{array}{llll}2.070 & 1.433 & 2.990 & <0.001\end{array}$

Friends' Smoking

More than half of my 1

friends

Less than half of my

friends

$\begin{array}{llll}0.128 & 0.088 & 0.186 & <0.001\end{array}$

No

$0.019 \quad 0.008$

0.044

$<0.001$

Teachers' smoking

No

Yes

$\begin{array}{llll}1.972 & 1.229 & 3.165 & 0.005\end{array}$

Model 2: The impact of awareness of the health hazards

\section{Gender}

Male

1

Female

0.805

$0,609 \quad 1,064$

0.127

\section{I}

Independent Variable

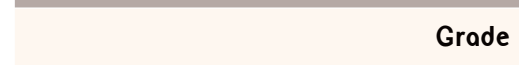

1st Grade of Gymnasium 1

2nd Grade of Gymnasium 2.5

3rd Grade of Gymnasium

2.549

1.112

5,839

0.027

1st Grade of Lyceum

6.303

1.177

6,185

0.019

2nd Grade of Lyceum

7.150

$2.943 \quad 13,498$

$<0.001$

3rd Grade of Lyceum

13.966

3.345

15,283

$<0.001$

Smoking is addictive

No

1

Yes

I don't know

0.331

0.220

0.496

$<0.001$

0.501

$0.241 \quad 1.040$

0.064

Occasional smoking is addictive

No

1

Yes

0.485

0.355

0.661

$<0.001$

I don't know

0.412

$0.258 \quad 0.657$

$<0.001$

\section{Smoking causes stroke}

No

$\begin{array}{lllll}\text { Yes } & 0.497 & 0.291 & 0.848 & 0.010\end{array}$

I don't know

0.453

0.259

0.792

0.006

Smoking harms the physical endurance of athletes

$\begin{array}{lllll}\text { No } & 1 & & & \\ \text { Yes } & 0.240 & 0.104 & 0.554 & 0.001 \\ \text { I don't know } & 0.352 & 0.109 & 1.135 & 0.08\end{array}$

Smoking causes premature aging

No 1

Yes

$\begin{array}{llll}0.308 & 0.139 & 0.686 & 0.004 \\ 0.327 & 0.142 & 0.757 & 0.009\end{array}$

I don't know

$\begin{array}{lll}0.327 & 0.142-0.757\end{array}$

0.009

(a) Individuals who responded that they had smoked at least one cigarette during the past 30 days.

smoking. The odds of being a current smoker rose in a linear fashion with increasing age to reach $11.5(\mathrm{OR}=11.59$; $95 \%$ CI $[6.24,21.49])$ among graduating students compared with students in the 1st grade of gymnasium.

We examined the independent association of variables of social origin with current smoking status in a multiple logistic regression analysis. As shown in Table 3, compared to students with non-smoking parents, students who had at least one parent a smoker were 1.71 times more likely to smoke
$(\mathrm{OR}=1.71 ; 95 \%$ CI $[1.19,2.46])$. Having siblings that smoke was associated with a 2 -fold risk of current smoking $(\mathrm{OR}=2.07$; 95\% CI [1.43, 2.99]). Participants who reported that less than half of their friends smoke were less likely to smoke themselves ( $\mathrm{OR}=0.13 ; 95 \%$ CI [0.09-0.19]). Finally, teachers' smoking status emerged as strongly associated with current smoking ( $\mathrm{OR}=1.97$; CI [1.23, 3.17]).

As seen in Table 3, students were less likely to be current smokers if they were aware of the addictiveness of tobacco $(\mathrm{OR}=0.33 ; 95 \%$ 
CI [0.22, 0.49]), the harmful effects of smoking on the physical endurance of athletes $(\mathrm{OR}=0.24 ; 95 \%$ CI $[0.10,0,55])$, the causal relationship between smoking and stroke $(\mathrm{OR}=0.49$; 95\% CI [0.29, 0.84]) and the causal relationship between smoking and premature aging $(\mathrm{OR}=0.3 ; 95 \%$ CI $[0.13$, $0.68]$ ).

Finally, students who reported exposure to smoking through entertainment media were more likely to be current smokers $(\mathrm{OR}=1.48 ; 95 \% \mathrm{CI}[1.03,2.14]$, whilst those reporting being exposed to promotion activities of the tobacco industry had almost a four -fold rise in risk $(\mathrm{OR}=3.73$; 95\% CI [2.88, 4.83].

\section{DISCUSSION}

Our results indicated that approximately 2 in 10 Greek urban adolescents are current cigarette smokers. Boys differ from girls by about 4 percentage points and cigarette smoking rates increase as passing from one grade to another. Of those tobacco products investigated, the cigarette emerged as the most likely product of experimentation followed by the hookah, the electronic cigarette, the cigar and the pipe. Increasing age, parental smoking as well as siblings, friends and teachers smoking, exposure to smoking through entertainment media and exposure to promotion activities of the tobacco industry proved strong predictors of current smoking for Greek teenagers.

A lower prevalence of current smoking was observed among adolescents of female gender and among those that reported a high rate of awareness regarding the specific health hazards of smoking.

In our study, rates of current cigarette smoking among the urban adolescent population in Greece is lower than previously reported ${ }^{4,16}$. The descending trend of current cigarette smoking was reported recently for the Greek population among young adults $^{17}$, whereas similar conclusions can be drawn from the GYTS $^{6,7}$. Part of this descending trend could be attributed to the measures that Greece has enforced as part of its conventional obligations within the World Health organization (WHO) Framework Convention on Tobacco Control (FCTC). In addition, over recent years Greece has been a target country for initiatives aimed at eliminating the tobacco epidemic through clean indoor air laws, increases in tax price, school education and media campaigns ${ }^{18}$.

With regards to gender differences, male gender remains a risk factor for current cigarette smoking although an ascending trend in the prevalence of tobacco use among young girls is present with European countries. This consistent finding for the Greek adolescent population should be taken into account in order to implement effective interventions.
A novel finding of this survey is the percentage of Greek teenagers experimenting with electronic cigarettes. A similar rate of experimentation with electronic cigarette was reported by a study among Finnish students ${ }^{19}$. It is common knowledge that debate exists with regards to the use and utility of electronic cigarettes and hence it is of critical importance to collect data on how adolescents respond to this new product. Although limited in number, studies conducted so far suggest an increasing trend of electronic cigarette use among adolescents and raise concerns regarding dual use, i.e. the concurrent use of traditional cigarette and electronic cigarette, and "gateway effects". It is interesting to stress that a notable proportion of our sample who had experimented with electronic cigarette had never smoked a traditional cigarette. In addition to the risk of engaging in a potentially addictive behavior, electronic cigarette use has been proven to cause immediate adverse physiologic effects even after short term use ${ }^{20}$.

Our cross-sectional study demonstrated that smoking status is associated with increasing age. The significant role of age has been confirmed by previous international ${ }^{21-24}$ as well as Greek studies ${ }^{5,9}$. Our findings regarding the prevalence of smoking within families and peer groups confirm previous studies in a national and international level ${ }^{8,9,25-30}$ all of which support the social origin of smoking. As suggested by the social cognitive theory, modelling is a corner stone of personal development ${ }^{31}$; hence approval of smoking by significant people in the life of an adolescent probably impacts adolescents' health behavior. In the same spirit, this study highlighted the important role of Greek teachers as health models for their students. The relationship between teachers' smoking and students' cigarette smoking highlights the great influence of the educational staff on the health behavior of adolescents and is in line with previous published European data $^{32}$. Few studies have investigated the influence of teachers smoking on the adolescents smoking behavior and to our knowledge this is the first to explore this issue on a sample of Greek urban students. Enforcing tobacco-free school policies in Greece emerges as a top public health priority.

Our results also provide empirical support to prevention programs that incorporate information curricula in their activities despite the fact that standalone information curricula interventions do not constitute successful smoking prevention interventions ${ }^{33}$. Awareness of specific health hazards in our study was proved to be a protective factor against engaging in cigarette smoking. This is a finding previously reported ${ }^{34}$ that points to the integration of information on health hazards of all tobacco products, as well as electronic cigarette, in schools' curriculum. 
Exposure to smoking through entertainment media (cinema movies, television series and/or video clips) is a consistent predictive indicator of initiation and regular use of tobacco products ${ }^{35}$ as further confirmed by our results. It is of great importance to note that according to a recent review, since 2002 the exposure rate of adolescents in smoking through movies is similar to that existed in $1950^{36}$. European youths in particular, are at greater risk of being exposed to smoking through movies as compared to the adolescents living in the United States of America due to non-compliance of some European countries with the WHO recommendations on restricting youth access to movies that portray smoking ${ }^{37}$. Strong and consistent evidence render tobacco promotional activities as a factor that leads to the initiation of smoking as well as its continuation ${ }^{38,39}$ with tobacco industry promotional activities noted as the strongest predictor of current cigarette smoking for Greek urban adolescents. This is another novel finding of the present study that provides sound evidence of the impact of the tobacco industry on Greek adolescents and points out the need to enforce bans on tobacco advertising, promotion and sponsorship.

It is important to note that the current study investigated students of the two major cities of Greece; therefore our findings are limited to the urban adolescent population. A nationwide representative sample should be considered in future studies as well as the addition of variables exploring socio-economic status, the initiation of smoking in this population, the prevalence of smoking in vocationally trained individuals versus those who continue on to lyceum and the use of other tobacco products for the investigation of the so called "gateway effect". Finally, the design of a longitudinal protocol it is likely to elucidate and deepen our knowledge on the topic and hence should be initiated.

\section{CONCLUSIONS}

Current cigarette smoking was reported by $18.2 \%$ of students aged 12-18 years old within the two major cities of Greece. The highest rate of smoking (35.3\%) was reported by the senior students, yet experimentation with many tobacco products was observed at all ages. Experimentation with electronic cigarettes was reported by $17,7 \%$ of the sample. Older age, parental, siblings', friends' and teachers' smoking, as well as exposure to smoking through entertainment media and through the promotion activities of the tobacco industry emerged as predictors of current cigarette smoking. Female students and those aware of the health hazards of smoking were less likely to be smokers.

\section{REFERENCES}

1. Lenney W, Enderby B. "Blowing in the wind": a review of teenage smoking. Archives of disease in childhood. 2008;93(1):72-5. doi: 10.1136/adc.2006.109702

2. Peto R, Lopez, AD. The future worlwide health effects of current smoking patterns. Tobacco: Science, policy and public health. New York: Oxford University Press; 2004.

3. Prevalence of current tobacco use among adolescents aged 13-15 years: World Health Organization European Region; Available from: http://www.euro.who.int/en/health-topics/disease-prevention/ tobacco/data-and-statistics/who-is-smoking/adolescents. (accessed 06 Nov 2014)

4. Arvanitidou M, Tirodimos I, Kyriakidis I, Tsinaslanidou Z, Seretopoulos D, Dardavessis T. Cigarette smoking among adolescents in Thessaloniki, Greece. International journal of public health. 2008;53(4):204-7.

doi: $10.1007 / \mathrm{s} 00038-008-8001-5$

5. Giannakopoulos G, Panagiotakos D, Mihas C, Tountas Y. Adolescent smoking and health-related behaviours: interrelations in a Greek school-based sample. Child: care, health and development. 2009;35(2):164-70. doi: 10.1111/j.1365-2214.2008.00906.x

6. Kyrlesi A, Soteriades ES, Warren CW, Kremastinou J, Papastergiou P, Jones NR, et al. Tobacco use among students aged 13-15 years in Greece: the GYTS project. BMC public health. 2007;7:3. doi:10.1186/1471-2458-7-3

7. Tobacco use among students aged 13-15 years in Greece: The GYTS project. [press release]. Athens, 27/01/2014 2014.

8. Rachiotis G, Muula AS, Rudatsikira E, Siziya S, Kyrlesi A, Gourgoulianis K, et al. Factors associated with adolescent cigarette smoking in Greece: results from a cross sectional study (GYTS Study). BMC public health. 2008;8:313.

doi:10.1186/1471-2458-8-313

9. Damianaki A, Kaklamani S, Tsirakis S, Clarke R, Tzanakis N, Makris D. Risk factors for smoking among school adolescents in Greece. Child Care Health and Development. 2008;34(3):310-5. doi: 10.1111/j.1365-2214.2008.00839.x.

10. Vardavas CI, Agaku I, Patelarou E, Anagnostopoulos N, Nakou C, Dramba V, et al. Ashtrays and signage as determinants of a smokefree legislation's success. PloS one. 2013;8(9):e72945. doi: 10.1371/journal.pone.0072945

11. National Health Interview Survey, Methodology Report. National Youth Tobacco Survey, Centers for Disease Control and Prevention, 2009b.

12. Johnston L, O'Malley, PM., Backman, JG., Schulenberg, JE. Monitoring the Future National Survey Results on Drug Use, 1975-2010. Bethesda MD: US: Department of Health and Human Services, National Institutes on Health, National Institute on drug Abuse 2011a.

13. Tobacco Free Initative Meeting on Tobacco and Religion. Geneva, Switzerland: World Health Organization, 19993 May. Report No.: WHO Report WHO/NCD/TFI/99.12.

14. Goldberg ME, Baumgartner H. Cross-country attraction as a motivation for product consumption. Journal of Business Research. 2002;55(11):901-6. HYPERLINK "http://dx.doi.org/10.1016/ S0148-2963(01)00209-0"doi:10.1016/S0148-2963(01)00209-0

15. Pierce JP, Choi WS, Gilpin EA, Farkas AJ, Berry CG. Tobacco industry promotion of cigarettes and adolescent smoking. Jama. 1998;279(7):511-5.

doi:10.1001/jama.279.7.511 
16. Kokkevi A, Terzidou M, Politikou K, Stefanis C. Substance use among high school students in Greece: outburst of illicit drug use in a society under change. Drug and alcohol dependence. 2000;58(12):181-8.

17. Filippidis FT, Vardavas CI, Loukopoulou A, Behrakis P, Connolly GN, Tountas Y. Prevalence and determinants of tobacco use among adults in Greece: 4 year trends. European journal of public health. 2013;23(5):772-6.

doi: 10.1093/eurpub/cks148

18. Vardavas C, Behrakis P. Greece: consumption down at last. Tobacco control. 2012;21:2.

19. Kinnunen JM, Ollila H, El-Amin SE, Pere LA, Lindfors PL, Rimpela $\mathrm{AH}$. Awareness and determinants of electronic cigarette use among Finnish adolescents in 2013: a population-based study. Tobacco control. 2014. doi: 10.1136/tobaccocontrol-2013-051512

20. Vardavas CI, Anagnostopoulos N, Kougias M, Evangelopoulou V, Connolly GN, Behrakis PK. Short-term pulmonary effects of using an electronic cigarette: Impact on respiratory flow resistance, impedance, and exhaled nitric oxide. Chest. 2012;141(6):1400-6. doi: $10.1378 /$ chest.11-2443

21. Bauman A, Phongsavan P. Epidemiology of substance use in adolescence: prevalence, trends and policy implications. Drug and alcohol dependence. 1999;55(3):187-207. doi: HYPERLINK “http://dx.doi.org/10.1016/S0376-8716(99)00016-2" 10.1016/ S0376-8716(99)00016-2

22. Rudatsikira E, Muula AS, Siziya S. Prevalence, correlates of and perceptions toward cigarette smoking among adolescents in South Korea. The Indian Journal of Pediatrics. 2009;76(5):505-10. doi: 10.1007/s12098-009-0073-6

23. Rudatsikira E, Abdo A, Muula AS. Prevalence and determinants of adolescent tobacco smoking in Addis Ababa, Ethiopia. BMC public health. 2007;7(1):176.

doi: HYPERLINK "http://dx.doi.org/10.1186\%2F1471-2458-7176"10.1186/1471-2458-7-176

24. Young S, Corley R, Stallings M, Rhee S, Crowley T, Hewitt J. Substance use, abuse and dependence in adolescence: prevalence, symptom profiles and correlates. Drug and alcohol dependence. 2002;68(3):309-22. HYPERLINK "http://dx.doi.org/10.1016/ S0376-8716(02)00225-9"doi:10.1016/S0376-8716(02)00225-9

25. Conrad KM, Flay BR, Hill D. Why children start smoking cigarettes: predictors of onset. British journal of addiction. 1992;87(12):171124. doi: 10.1111/j.1360-0443.1992.tb02684.x

26. Tyas SL, Pederson LL. Psychosocial factors related to adolescent smoking: a critical review of the literature. Tobacco control. 1998;7(4):409-20. doi:10.1136/tc.7.4.409

27. Villanti A, Boulay M, Juon H-S. Peer, parent and media influences on adolescent smoking by developmental stage. Addictive behaviors. 2011;36(1):133-6. doi: 10.1016/j.addbeh.2010.08.018

28. McVicar D. Estimates of peer effects in adolescent smoking across twenty six European countries. Social Science \& Medicine. 2011;73(8):1186-93. HYPERLINK "http://dx.doi.org/10.1016/ j.socscimed.2011.08.006"doi:10.1016/j.socscimed.2011.08.006

29. Avenevoli S, Merikangas KR. Familial influences on adolescent smoking. Addiction (Abingdon, England). 2003;98:1-20. doi: 10.1046/j.1359-6357.2003.00586.x

30. Whitesell M, Bachand A, Peel J, Brown M. Familial, Social, and Individual Factors Contributing to Risk for Adolescent Substance Use. Journal of Addiction. 2013;2013:9 HYPERLINK "http:// dx.doi.org/10.1155/2013/579310" doi: 10.1155/2013/579310

31. Bandura A. Social foundations of thought and action, a social cognitive theory. Englewood Cliffs, New Jersey: Prentice Hall; 1986.

32. Poulsen LH, Osler M, Roberts C, Due P, Damsgaard MT, Holstein BE. Exposure to teachers smoking and adolescent smoking behaviour: analysis of cross sectional data from Denmark. Tobacco control. 2002;11(3):246-51. doi: HYPERLINK "http://dx.doi.org/ 10.1136\%2Ftc.11.3.246"10.1136/tc.11.3.246

33. Thomas RE, McLellan J, Perera R. School-based programmes for preventing smoking. The Cochrane database of systematic reviews. 2013;4:Cd001293. doi: 10.1002/14651858.CD001293

34. Steptoe A, Wardle J, Cui W, Baban A, Glass K, Tsuda A, et al. An international comparison of tobacco smoking, beliefs and risk awareness in university students from 23 countries. Addiction (Abingdon, England). 2002;97(12):1561-71. doi: 10.1046/j.1360-0443.2002.00269.x

35. Dalton MA, Beach ML, Adachi-Mejia AM, Longacre MR, Matzkin AL, Sargent JD, et al. Early exposure to movie smoking predicts established smoking by older teens and young adults. Pediatrics. 2009;123(4):e551-8. doi: 10.1542 peds.2008-2102

36. Charlesworth A, Glantz SA. Smoking in the movies increases adolescent smoking: a review. Pediatrics. 2005;116(6):1516-28. doi: 10.1542/peds.2005-0141

37. Hanewinkel R, Sargent JD, Karlsdottir S, Jonsson SH, Mathis F, Faggiano F, et al. High youth access to movies that contain smoking in Europe compared with the USA. Tobacco control. 2013;22(4):241-4.

doi:10.1136/tobaccocontrol-2011050050

38. Institute of Medicine Committee on Preventing Nicotine Addiction in C, Youths. In: Lynch BS, Bonnie RJ, editors. Growing up Tobacco Free: Preventing Nicotine Addiction in Children and Youths. Washington (DC): National Academies Press (US)

39. Lovato C, Linn G, Stead LF, Best A. Impact of tobacco advertising and promotion on increasing adolescent smoking behaviours. The Cochrane database of systematic reviews. 2003(4):Cd003439.

doi: 10.1002/14651858.CD003439

\section{ACKNOWLEDGEMENTS}

The authors are deeply thankful to all participants, especially students who volunteered to participate, health educators, school principals and personnel of selected schools, since without their willingness, readiness and understanding the project could not have been implemented.

\section{CONFLICT OF INTEREST}

The authors have completed and submitted the ICMJE Form for Disclosure of Potential Conflicts of Interest and none were reported.

\section{FUNDING}

This work was supported by an ESPA grant (MIS 372829) and the George Behrakis Foundation, Boston, USA through the Hellenic Action for Research Against TobaccoII project (HEART-II).

PROVENANCE AND PEER REVIEW

Not commissioned; externally peer reviewed 